\title{
Eficácia da ação antimicrobiana do extrato de própolis de abelha jataí (Tetragonisca angustula) em bactérias Gram-positivas e Gram-negativas
}

\author{
Diego Groto Barreiras ${ }^{1}$, Flávia Montanari Ruiz², José Erick Galindo Gomes³ ${ }^{3}$ Bruna Maria Salotti de Souza ${ }^{4 *}$
}

\begin{abstract}
Resumo
A própolis é produzida pelas abelhas e corresponde a um material proveniente da coleta de secreções resinosas vegetais, com adição de enzimas salivares e cera na composição do produto final, são atribuídas diversas propriedades biológicas a própolis, dentre elas um potencial de atividade antimicrobiana que vem sendo amplamente estudada, uma vez que, a descoberta de princípios ativos antibacterianos, trouxe significativos avanços para a área da saúde. O presente trabalho teve por objetivo avaliar a eficácia antimicrobiana de seis diferentes concentrações de extrato de própolis de abelha Jataí em bactérias Gram-positivas e Gram-negativas, para isso foram coletadas 20 amostras de própolis, produzidas em meliponários localizados em Uchoa - SP e Tabapuã - SP, nos meses de dezembro 2018 a março de 2019. O extrato hidroetanólico mostrou efetividade antimicrobiana frente aos micro-organismos Gram-positivos e Gram-negativos testados, onde $E$. coli e $P$. aeruginosa foram sensíveis a quatro das seis concentrações e a CIM foi de $125 \mu \mathrm{g} / \mathrm{mL}$, já a K. pneumoniae apresentou maior sensibilidade entre as cepas Gram-negativas, assim como as três bactérias Gram-positivas, tiveram inibição de crescimento por cinco das concentrações testadas e CIM de 62,5 $\mu \mathrm{g} /$ $\mathrm{mL}$. Dessa forma foi possível concluir que o extrato hidroetanólico da própolis de abelha Jataí apresentou substâncias capazes de inibir o crescimento de todas as bactérias testadas e os baixos valores de CIM indicam uma promissora possibilidade de uso deste material biológico como alternativa ao uso de antibióticos, contribuindo também para a redução da resistência microbiana.
\end{abstract}

Palavras-chave: Antibióticos. Antimicrobianos naturais. Resistência bacteriana. Saúde Pública.

\section{Effectiveness of antimicrobian action of jataí bee (Tetragonisca angustula) propolis extract in Gram-positive and Gram-negative bacteria}

\begin{abstract}
Propolis is produced by bees and corresponds to a material derived from the collection of resinous plant secretions, with the addition of salivary enzymes and wax in the final product composition. Propolis is attributed several biological properties, among them a potential for antimicrobial activity that has been It has been widely studied, since the discovery of antibacterial active ingredients has brought significant advances in healthcare. The present work aimed to evaluate the antimicrobial efficacy of six different concentrations of Jataí bee propolis extract in Gram-positive and Gram-negative bacteria. Twenty propolis samples were collected from meliponaria located in Uchoa - SP and Tabapuã. SP from December 2018 to March 2019. Hydroethanolic extract showed antimicrobial effectiveness against the Gram-positive and Gram-negative microorganisms tested, where E. coli and P. aeruginosa were sensitive to four of the six concentrations and to MIC was $125 \mu \mathrm{g} / \mathrm{mL}$, whereas K. pneumoniae showed higher sensitivity among Gram-negative strains, as well as the three Gram-positive bacteria, had growth inhibition by five of the tested concentrations and MIC of $62.5 \mu \mathrm{g} / \mathrm{mL}$. Thus, it was concluded that the hydroethanolic extract of Jataí bee propolis presented substances
\end{abstract}

\footnotetext{
${ }^{1}$ Centro Universitário do Norte Paulista. São José do Rio Preto, SP. Brasil

http://orcid.org/000-0002-7161-1883

${ }^{2}$ Centro Universitário do Norte Paulista. São José do Rio Preto, SP. Brasil. http://orcid.org/000-0001-9697-9783

${ }^{3}$ Centro Universitário do Norte Paulista. São José do Rio Preto, SP. Brasil. http://orcid.org/000-0001-5444-8714

4Universidade Federal de Minas Gerais. Belo Horizonte, MG. Brasil.

http://orcid.org/0000-0002-6176-2426

*Autor para correspondência: salottibm@yahoo.com.br
}

Recebido para publicação em 01 de novembro de 2019. Aceito para publicação em 04 de janeiro de 2020. e-ISSN: 2447-6218 / ISSN: 2447-6218. Atribuição CC BY. 
Barreiras, D. G. et al.

capable of inhibiting the growth of all bacteria tested and the low MIC values indicate a promising possibility of using this biological material as an alternative to the use of antibiotics. for reducing microbial resistance.

Keywords: Antibiotics. Natural antimicrobials. Bacterial resistance. Public health.

\section{Introdução}

Amplamente distribuída no território brasileiro, a meliponínea da espécie Tetragonisca angustula, conhecida popularmente por Jataí, é uma das espécies mais abundantes nos neotrópicos. É considerada uma espécie de pequeno porte, importante para os ecossistemas devido seu alto potencial polinizador e considerada alvo de pesquisas cientificas pela produção de mel e própolis com relevantes propriedades medicinais (Jacob et al., 2019; Nogueira-Neto, 1997).

A própolis é formada pela mistura de secreções de árvores e plantas coletadas por abelhas com pólen e enzimas, apresentando composição que depende da origem geográfica e botânica, estação de coleta e condições climáticas (Vasilaki et al., 2019). Além disso, a própolis contém uma alta concentração de terpenóides que possuem efeitos bacteriostáticos e bactericidas e atua como agente antimicrobiano, sensibilizando a camada fosfolipídica das células, o que promove um aumento da permeabilidade e perda de componentes intracelulares, levando a morte das células (Salazar et al., 2018).

A própolis foi descrita por sua capacidade inibitória da multiplicação de bactérias Gram-positivas, não possuindo potencialmente a mesma intensidade nas bactérias Gram-negativas, provavelmente devido à complexidade química de sua parede celular (Nogueira e Miguel, 2009; Orsi, 2000).

No ano de 2019 foi apresentada a estimativa de que aproximadamente $14 \%$ dos indivíduos hospitalizados ou submetidos a alguma intervenção médica venham a adquirir infecções hospitalares e dentre os micro-organismos envolvidos com maior incidência estão os Gram-negativos como Escherichia coli, Klebisiela pneumoniae e Pseudomonas aeruginosa e os micro-organismos Gram-positivos oportunistas de importância clínica que destacam-se, Staphylococcus aureus, Enterococcus faecalis e Bacillus subtilis (Beraldo e Souza, 2019, Brasil, 2004).

Com a finalidade de tratamento das doenças infecciosas tem-se observado o uso excessivo e sem cuidadosa avaliação de diversos grupos de antimicrobianos, tornando propício o desenvolvimento de resistência bacteriana (Kadosaki et al., 2012). Segundo a Organização Mundial da Saúde, a resistência bacteriana a medicamentos deveria ser vista como um problema de saúde pública, já que se trata de uma prática pouco recente (OMS, 2010).

Como atualmente não há desenvolvimento de novos antibióticos, a resistência antimicrobiana pode gerar uma alta proliferação de "superbactérias" e, no futuro, diminuir ou mesmo eliminar as chances de tratamento eficaz de doenças desses patógenos multirresistentes (Cho e Tasho, 2016).

Com base no exposto, o presente trabalho teve por objetivo avaliar a eficácia antimicrobiana de seis diferentes concentrações de extrato de própolis de abelha Jataí (Tetragonisca angustula) em bactérias Gram-positivas e Gram-negativas.

\section{Material e Métodos}

\section{Coleta de amostras}

Foram coletadas 20 amostras de própolis de abelha Jataí, produzidas em meliponários localizados em Uchoa - SP e Tabapuã - SP em caixas do tipo AF, nos meses de dezembro 2018 a março de 2019. Durante as coletas nos apiários, foram feitos os registros referentes à localização, condições do enxame, floradas, condições climáticas durante a coleta e demais observações pertinentes que pudessem interferir na característica da própolis coletada.

Após coleta até a preparação do extrato, a própolis foi acondicionada em frascos estéreis e armazenados à temperatura de $5+/-3^{\circ} \mathrm{C}$. Posteriormente, as amostras foram inspecionadas para retirada de impurezas como madeira, abelhas mortas e ceras e mantidas à temperatura de $-4^{\circ} \mathrm{C}$ até o momento do preparo do extrato etanólico.

\section{Preparação do Extrato Hidroetanólico de Própolis}

Os extratos hidroetanólicos da própolis foram produzidos pelo padrão oficial para o extrato conforme metodologia descrita na Instrução Normativa no 3 , de 19/01/2001, do Departamento de Inspeção de Produtos de Origem Animal, do Ministério da Agricultura, Pecuária e Abastecimento-MAPA, com maceração a frio de $300 \mathrm{~g}$ de própolis bruta em $700 \mathrm{~mL}$ de etanol 70\% PA, sendo as 20 amostras misturadas em um extrato (Brasil, 2001).

A preparação foi estocada em temperatura ambiente e protegida da luz por um período de 45 dias. Após este período, o extrato foi filtrado com o auxílio de um funil e filtro de papel previamente autoclavados e mantidos à temperatura de $5+/-3^{\circ} \mathrm{C}$ em frascos âmbar. Posteriormente, o extrato hidroetanólico a $70 \%$ foi ajustado para uma concentração alcoólica final de $20 \%$ adicionando-se água. A partir desta solução, foram rea- 
Eficácia da ação antimicrobiana do extrato de própolis de abelha jataí (Tetragonisca angustula) em bactérias Gram-positivas e Gram-negativas

lizadas diluições seriadas em etanol 20\%, sendo padronizadas seis diferentes concentrações finais de extrato de própolis de abelha Jataí (1000, 500, 250, 125, 62,5 e $31,25 \mu \mathrm{g}$ própolis/mL).

\section{Cultura microbiana}

Foram utilizadas três cepas de bactérias Gram-positivas (Bacillus subtilis UFPEDA 86, Staphylococcus aureus UFPEDA 02, Enterococcus faecalis UFPEDA 138) e três cepas de bactérias Gram-negativas (Escherichia coli UFPEDA 224, Klebisiela pneumoniae UFPEDA 396 e Pseudomonas aeruginosa UFPEDA 416), às quais estavam armazenadas em caldo BHI (Brain Heart Infusion) (Difco) a $-80^{\circ} \mathrm{C}$, adicionadas de glicerol estéril como crioprotetor.

\section{Avaliação da atividade antimicrobiana}

A atividade antimicrobiana foi realizada no laboratório de Bioquímica e Microbiologia Aplicada (Ibilce/ UNESP) na cidade de São José do Rio Preto - SP. Foi utilizado o método de concentração inibitória mínima (CIM) por diluição em caldo, proposto pelo National Committee for Clinical Laboratory Standards (NCCLS) e aprovado pela Anvisa (Brasil, 2003).

As cepas selecionadas foram ativadas em caldo triptona de soja (TSB) e incubadas por 24 horas a $37^{\circ} \mathrm{C}$. Posteriormente, para a preparação e padronização do inóculo, uma alíquota de cada solução bacteriana foi colocada em $10 \mathrm{~mL}$ de TSB e incubada a $37^{\circ} \mathrm{C}$, até atingir a escala logarítmica de crescimento determinada por absorbância a $620 \mathrm{~nm}$ e padronizada uma quantidade de $10^{8} \mathrm{UFC} /$ mL (escala de Mc Farland). Microplacas de 96 poços de fundo plano, de poliestireno e estéreis, foram utilizadas para o ensaio. A mistura de $50 \mu \mathrm{L}$ de cada diluição do extrato hidroetanólico de própolis foi feita com $45 \mu \mathrm{L}$ de caldo Mueller Hinton (CMH) e $5 \mu \mathrm{L}$ da suspensão bacteriana. $\mathrm{O}$ controle positivo foi realizado com o objetivo de garantir que a presença de etanol não afetaria o crescimento bacteriano, sendo composto por $50 \mu \mathrm{L}$ de etanol $20 \%$ (em substituição à amostra), $45 \mu \mathrm{L}$ de caldo $\mathrm{CMH}$ e $5 \mu \mathrm{L}$ da suspensão bacteriana. Já para o controle negativo, utilizou-se $50 \mu \mathrm{L}$ do antibiótico cloranfenicol na concentração de $300 \mu \mathrm{g} / \mathrm{mL}$ diluído em etanol 20\%, $45 \mu \mathrm{L}$ de caldo $\mathrm{CMH}$ e $5 \mu \mathrm{L}$ da suspensão bacteriana. Todos os ensaios foram realizados em triplicata.

\section{Resultados e Discussão}

Os enxames se encontravam em região de mata na área rural, onde o pasto apícola se caracterizava por plantas nativas como cipó-uva, assa-peixe e aroeira, e culturas de seringueira e eucalipto. A coleta das amostras ocorreu no verão, no período da manhã em temperatura entre $20^{\circ} \mathrm{C}$. As colmeias foram selecionadas pela elevada população, produtividade de mel e própolis, sendo esses indicativos de boa saúde.

O extrato hidroetanólico da abelha Jataí criada em meliponários da região de Uchoa - SP e Tabapuã - SP, mostrou efetividade antimicrobiana frente aos micro-organismos Gram-positivos e Gram-negativos testados, confirmada pelos resultados de CIM na tabela 1 , onde K. pneumoniae apresentou maior sensibilidade entre as cepas Gram-negativas avaliadas, assim como as três bactérias Gram-positivas, tiveram inibição de crescimento por cinco das concentrações testadas e CIM de 62,5 $\mu \mathrm{g} /$ $\mathrm{mL}$. Já a E. coli e P. aeruginosa foram sensíveis a quatro das seis concentrações e a CIM foi de $125 \mu \mathrm{g} / \mathrm{mL}$.

Tabela 1 - Atividade antimicrobiana em bactérias Gram-positivas e Gram-negativas, de diferentes concentrações do extrato hidroetanólico de própolis de abelha Jataí.

\begin{tabular}{|c|c|c|c|c|c|c|}
\hline \multirow{2}{*}{ MICRO-ORGANISMOS } & \multicolumn{6}{|c|}{ CONCENTRAÇÃO $(\mu \mathrm{g} / \mathrm{mL})$} \\
\hline & 1000 & 500 & 250 & 125 & 62,5 & 31,25 \\
\hline Bacillus subtilis UFPEDA 86 & - & - & - & - & - & + \\
\hline Staphylococcus aureus UFPEDA 02 & - & - & - & - & - & + \\
\hline Enterococcus faecalis UFPEDA 138 & - & - & - & - & - & + \\
\hline Klebsiella pneumoniae UFPEDA 396 & - & - & - & - & - & + \\
\hline Escherichia coli UFPEDA 224 & - & - & - & - & + & + \\
\hline Pseudomonas aeruginosa UFPEDA 416 & - & - & - & - & + & + \\
\hline
\end{tabular}

Os símbolos (+) e (-) indicam a presença ou ausência de crescimento microbiano, respectivamente.

Farnesi (2007) através da técnica de microdiluição em caldo não obteve resultados significativos frente a amostras de extrato de própolis de abelhas T. angustula sobre E. coli, P. aeruginosa e Staphylococcus aureus com ausência inibitória em concentrações de até $400 \mu \mathrm{g} / \mathrm{mL}$. Já Lima (2015), mesmo com concentrações superiores a 15 $\mathrm{mg} / \mathrm{mL}$ da geoprópolis da mesma espécie de abelha, não obteve resultados satisfatórios de inibição. Diferentemente de Pereira et al., (2003), que avaliaram a sensibilidade de quatro cepas incluindo E. coli, S. aureus e B. subtilis e encontraram potencial efetividade da própolis dessa abelha em concentração de $180 \mu \mathrm{g} / \mathrm{mL}$ frente aos três 
Barreiras, D. G. et al.

dos micro-organismos em estudo, e ainda que $S$. aureus apresentou a maior sensibilidade.

Resultados obtidos por Campos et al., (2015) com própolis proveniente do estado do Mato Grosso do Sul corroboram com o presente trabalho, demonstrando que entre os micro-organismos em comum avaliados a sensibilidade inibitória ocorreu em ordem decrescente para $S$. aureus, E. faecalis, $K$. pneumoniae e P. aeruginosa. $\mathrm{O}$ efeito bactericida observado pelos autores variou entre $1,5 \pm 0,14 \mathrm{mg} / \mathrm{mL}$ para $S$. aureus e $15,50 \pm 0,20 \mathrm{mg} / \mathrm{mL}$ para $P$ aeruginosa. Vale ressaltar que, como mostrado por Fernandes Jr. et al., (2006), existe uma complexidade sobre o mecanismo de atividade antimicrobiana da própolis, a qual é atribuída ao sinergismo entre os flavonoides, hidroxiácidos e sesquiterpenos. Os autores afirmam ainda que a concentração destas substâncias presentes na própolis varia de acordo com a localização geográfica e a época de coleta, o que confere consequentemente interferências sobre a eficiência da inibição do crescimento bacteriano. Desta forma, a origem da própolis é um dos fatores mais importantes no controle de qualidade para a sua efetiva ação contra estes tipos de micro-organismos.

Como evidenciado por Castro et al., (2007), as explicações para as diferenças de resultados quanto à efetividade da atividade antimicrobiana do extrato de própolis estão na diversificação química da própolis correlacionada a fatores geográficos, climáticos e à sazonalidade influente sobre as plantas que fornecem a matéria prima resinosa para essa substância, o que torna laboriosa a padronização do produto. Pereira et al., (2002), relevam ainda a capacidade bioquímica de transformação da resina e adição de compostos salivares próprios das abelhas em suas variações de espécies pelo país.

Amarante et al., (2019), trabalhando com cepas multirresistentes de Staphylococcus spp. isolados de bovi- nos com mastite subclínica, apresentaram resultados de completa inibição do crescimento desta bactéria utilizando extrato de própolis com concentração de $68,7 \mu \mathrm{g} / \mathrm{mL}$. Isto ressalta a importância da utilização do extrato de própolis como alternativa ao uso de antibióticos convencionais.

Fernandes Jr. et al., (2001), Campos et al., (2015), Lima (2015) e Pereira et al., (2003), descrevem a maior sensibilidade dos micro-organismos Gram-positivos às amostras de própolis e limitações na efetividade contra Gram-negativas. Essa restrição inibitória pode ser atribuída às diferenças químicas presentes na parede celular desses micro-organismos como a camada de peptideoglicano que reveste a membrana externa das bactérias Gram-negativas que podem ser a razão da baixa sensibilidade das bactérias Gram-negativas a fatores externos como óleos essenciais e extratos (Seibert et al., 2019).

Segundo Lustosa et al., (2008), o potencial antimicrobiano da própolis é atribuído aos seus principais constituintes, como os flavonoides, flavononas, ácidos aromáticos e ésteres. Sugere-se que estas substâncias são capazes de desempenhar atividade inibitória da RNA-polimerase bacteriana, além de alterações estruturais e funcionais da parede celular, interferindo diretamente nos processos de divisão celular e osmolaridade, levando à bacteriólise, como mostrado em estudos realizados por Takaisi-Kikuni e Schilcher (1994).

\section{Conclusão}

Com base nos resultados obtidos para a atividade antimicrobiana, o extrato hidroetanólico da própolis de abelha Jataí apresentou substâncias capazes de inibir o crescimento de todas as bactérias testadas e os baixos valores de concentração inibitória mínima indicam uma promissora possibilidade de uso deste material biológico como alternativa ao uso de antibióticos, contribuindo ainda para a redução dos processos de resistência microbiana, frequentemente relatada como um problema de Saúde Pública.

\section{Referências}

Amarante, J. F.; Ribeiro, M. F.; Costa, M. M.; Menezes, F. G.; Silva, T. M. S.; Amarante, T. A. B.; Gradela, A.; Moura, L. M. D. 2019. Chemical composition and antimicrobial activity of two extract of propolis against isolates of Staphylococcus spp. and multiresistant bacterials. Pesquisa Veterinária Brasileira, 39:734-743. Doi: http:// dx.doi.org/10.1590/1678-5150-pvb-6128.

Beraldo, N.; Souza, T. 2019. Projetos de UTIs de 119 hospitais permite salvar 558 vidas. Disponível em: http://www.saude.gov.br/noticias/ agencia-saude/45309-projeto-em-utis-de-119-hospitais-permitiu-salvar558-vidas.

Brasil. Agencia Nacional de Vigilância Sanitária 2003. Metodologia dos Testes de Sensibilidade a Agentes Antimicrobianos por Diluição para Bactéria de Crescimento Aeróbico, Brasília. Disponível em: http:// www.anvisa.gov.br/servicosaude/manuais/clsi/clsi_opasm7_a6.pdf.
Brasil. Agencia Nacional de Vigilância Sanitária 2004. Manual de Microbiologia Clínica para o Controle de Infecção em Serviços de Saúde. Brasília. Disponível em: https://bvsms.saude.gov.br/bvs/publicacoes/ manual_microbiologia_completo.pdf.

Brasil. Ministério da Agricultura, Pecuária e Abastecimento. Instrução Normativa no 3, de 19 de janeiro de 2001. Regulamentos técnicos de identidade e qualidade de apitoxina, cera de abelha, geleia real, geleia real liofilizada, pólen apícola, própolis e extrato de própolis. Diário Oficial da República Federativa do Brasil, Brasília, DF, jan. 2001. Seção 1, p. $18-23$.

Campos, J. F; Santos, U. P.; Rocha, P. S.; Damião, M. J.; Balestieri, J. B. P; Cardoso, C. A. L.; Paredes-Gamero, E. J.; Estevinho, L. M.; Picoli, S. K.; Santos, E. L. 2015. Antimicrobial, Antioxidant, Anti-Inflammatory, and Cytotoxic Activities of Propolis from the Stingless Bee Tetragonisca fiebrigi (Jataí). Evidence-based Complementary and Alternative Medicine. 2015:1-11. Doi: http://dx.doi.org/10.1155/2015/296186. 
Eficácia da ação antimicrobiana do extrato de própolis de abelha jataí (Tetragonisca angustula) em bactérias Gram-positivas e Gram-negativas

Castro, M. L.; Cury, J. A.; Rosalen, P. L.; Alencar, S. M.; Ikegaki, M.; Duarte, S.; Koo, H. 2007. Própolis do sudeste e nordeste do Brasil: influência da sazonalidade na atividade antibacteriana e composição fenólica. Química Nova, 30:1512-6. Doi: http://dx.doi.org/10.1590/ S0100-40422007000700003.

Cho, J. Y.; Tasho, R. P. 2016. Veterinary antibiotics in animal waste, its distribution in soil 357 and uptake by plants: A review. Science of the Total Environment, 563:366-376. Doi: https://doi.org/10.1016/j. scitotenv.2016.04.140.

Farnesi, A. P. 2007. Efeitos da própolis de abelhas africanizadas e meliponíneos em micro-organismos. Dissertação de mestrado. Área em Ciências- Genética, Universidade de São Paulo.

Fernandes Jr., A.; Lopes, M. M. R.; Colombari, V.; Monteiro, A. C. M.; Vieira, E. P. 2006. Atividade antimicrobiana de própolis de Apis mellifera obtidas em três regiões do Brasil. Ciência Rural, Santa Maria, 36:294 297. Doi: http://dx.doi.org/10.1590/S0103-84782006000100047.

Fernandes Jr, A.; Leomil, L.; Fernandes, A. A. H. 2001. The antibacterial activity of propolis produced by Apis mellifera L. and Brazilian stingless bees. The Journal of Venomous Animals and Toxins, 7:173-82. Doi: http://dx.doi.org/10.1590/S0104-79302001000200003.

Jacob, C. R. O.; Zanardi, O. Z.; Malaquias, J. B.; Silva, C. A. S.; Yamamoto, P. T. 2019. The impact of four widely used neonicotinoid insecticides on Tetragonisca angustula (Latreille) (Hymenoptera: Apidae). Chemosphere, 224:65-70. Doi: https://doi.org/10.1016/j. chemosphere.2019.02.105.

Kadosaki, L. L.; Sousa, S. F.; Borges, J. C. M. 2012. Análise do uso e da resistência bacteriana aos antimicrobianos em nível hospitalar. Revista Brasileira de Farmácia, 93:128-135. Diponível em: http://www.rbfarma. org.br/files/rbf-2012-93-2-1.pdf.

Lima, M. V. D. 2015. Geoprópolis produzida por diferentes espécies de abelhas: Atividade antimicrobiana e antioxidante e determinação do Teor de compostos fenólicos. Programa de pós-graduação. Área em Ciências Farmacêuticas. Universidade Federal do Pará. Disponível em: http:// www.ppgcf.propesp.ufpa.br/ARQUIVOS/dissertacoes/marcuslima.pdf.

Lustosa, S. R.; Galindo, A. B.; Nunes, L. C. C.; Randau, K. P.; Neto, P. J. R. 2008. Própolis: Atualizações sobre a química e farmacologia. Brazilian Journal of Pharmacognosy, 18:447-454. Doi: http://dx.doi. org/10.1590/S0102-695X2008000300020.
Nogueira, J. B. R.; Miguel, L. F. S. 2009. Bacteriologia: Citologia. In: Molinaro, E. M.; Caputo, L. F. G.; Amendoeira, M. R. R. Conceitos e Métodos para a Formação de Profissionais em Laboratórios de Saúde, v. 4. Rio de Janeiro: EPSJV, IOC, cap. 3, p. 221-397.

Nogueira-Neto, P. 1997. Vida e criação de abelhas indígenas sem ferrão. São Paulo: Editora Nogueirapis.

OMS Organização Mundial da Saúde. 2010. Advertência sobre doenças resistentes a medicamentos. Disponível em: http://unicrio.org.br/omsadverte-sobre-doencas-resistentes-a-medicamentos.

Orsi, R. O.; Funari, S. R. C.; Soares, A. M. V. C.; Calvi, S. A.; Oliveira, S. L.; Sforcin, J. M.; Bankova, V. 2000. Immunomodulatory action of propolis on macrophage activation. Journal of Venomous Animals and Toxins, 6. Doi: http://dx.doi.org/10.1590/S0104-79302000000200006.

Pereira, A. S., Seixas, F. R. M. S., Aquino-Neto, F. R. 2002. Própolis: 100 anos de pesquisa e suas perspectivas futuras. Química Nova, 25:321326. Doi: http://dx.doi.org/10.1590/S0100-40422002000200021.

Pereira, A. S.; Bicalho, B.; Aquino-Neto, F. R. 2003. Comparison of própolis from Apis mellifera and Tetragonisca angustula. Apidologie, 34:291-298. Doi: https://doi.org/10.1051/apido:2003023.

Salazar, G. J. T.; De Souza, J. P.; Lima, C. N. F; Lemos, I. C. S.; Da Silva, A. R. P. De Freitas, T. S.; Deschamps, C. 2018. Phytochemical characterization of the Baccharis dracunculifolia essential oil and antibacterial activity evaluation. Industrial Crops and Products, 122:591-595. Doi: https://doi.org/10.1016/j.indcrop.2018.06.052.

Seibert, J. B.; Bautista-Silva, J. P.; Amparo, T. R.; Petit, A.; Pervier, P; Almeida, J. C. S.; Azevedo, M. C.; Silveira, B. M.; Brandão, G. C.; Souza, G. H. B.; Teixeira, L. F. M.; Santos, O. D. H. 2019. Development of propolis nanoemulsion with antioxidant and antimicrobial activity for use as a potential natural preservative. Food Chemistry, 287:61-67. Doi: https://doi.org/10.1016/j.foodchem.2019.02.078.

Takaisi-Kikuni, N. B.; Schilcher, H. 1994. Electron microscopic and microcalorimetric investigations of the possible mechanism of the antibacterial action of a defined propolis provenance. Planta Med., 60:222-227. Doi: https://doi.org/10.1055/s-2006-959463.

Vasilaki, A.; Hatzikamari, M.; Stagkos-Georgiadis, A.; Goula, A. M.; Mourtzinos, I. 2019. A natural approach in food preservation: Propolis extract as sorbate alternative in non-carbonated beverage. Food Chemistry, 298. Doi: https://doi.org/10.1016/j.foodchem.2019.125080. 